\title{
EXEQUATUR DE SENTENCIA MARROQUI - DIVORCIO \\ Y ALIMENTOS: CITACIÓN LEGAL, FIRMEZA \\ Y EJECUCIÓN PROVISIONAL \\ (AUDIENCIA PROVINCIAL GIRONA - AUTO DE 08/10/2019)
}

\author{
MOROCCAN JUDGMENT EXEQUATUR ON DIVORCE \\ AND MAINTENANCE CLAIMS: SUBPOENA, DEFINITIVE \\ JUDGMENT AND PROVISIONAL EXECUTION \\ (GIRONA PROVINCIAL COURT - ORDER OF 08/10/2019)
}

\author{
Marina Vargas Gómez-UrRutia \\ Profesora Titular de Derecho internacional privado \\ Universidad Nacional de Educación a Distancia (UNED) \\ ORCID ID: 0000-0002-4574-341X
}

Recibido: 11.03.2020 / Aceptado: 03.04.2020

DOI: https://doi.org/10.20318/cdt.2020.5668

\begin{abstract}
Resumen: Este comentario tiene por objeto el examen del Auto de la Audiencia Provincial de Girona de 8 de octubre de 2019. La Audiencia contextualiza el régimen jurídico aplicable a la ejecución de una sentencia marroquí de divorcio con establecimiento de medidas de alimentos en el marco del Convenio hispano-marroquí de 1997. El análisis del cumplimiento y prueba de las condiciones para otorgar la autoridad de cosa juzgada en general y, en particular, la posibilidad de ejecución provisional de las medidas de alimentos en defecto de prueba de la firmeza constituye el núcleo de la controversia.

Palabras clave: reconocimiento y ejecución, divorcio y obligación de alimentos, Convenio hispano marroquí de 30/05/1997, requisitos para otorgar el exequatur, derechos de defensa y rebeldía, acreditación de la firmeza.
\end{abstract}

Abstract: This note is aimed at the Order of the Provincial Court of Girona of October 8, 2019. The Court adequately contextualizes the legal regime applicable to the recognition and enforcement of a Moroccan divorce and maintenance obligation and examines, in the light of the claims invoked, the conditions for its granting as well as the possibility of provisional execution even if it has not been proven that the sentence is final.

Keywords: recognition and enforcement, divorce and maintenance claims, Spanish-Moroccan Convention of $05 / 30 / 1997$, requests for recognition and enforcement, the right to be heard and default of appearance, definitive judgment.

Sumario: I. Las pretensiones invocadas ante la Audiencia Provincial de Girona y su auto de 8 de octubre de 2019. II. Las condiciones para otorgar el exequatur de la sentencia marroquí (I): las partes han sido legalmente citadas, representadas o declaradas rebeldes. III. Las condiciones para otorgar el exequatur de la sentencia marroquí (II): la resolución ha adquirido autoridad de cosa juzgada y ha llegado a ser ejecutiva conforme a las leyes del Estado en que haya sido dictada. IV. Reflexión conclusiva. 


\section{Las pretensiones invocadas ante la Audiencia Provincial de Girona y su Auto de 8 de octubre de $2019^{1}$}

1. El auto de la Audiencia Provincial de Girona de 8 de octubre de 2019 (en adelante, AAP Girona) se dicta en el marco de un procedimiento de exequátur de dos resoluciones dictadas por un tribunal de primera instancia de Nador (Marruecos). La primera, de 26 de enero de 2016, "sobre fijación de pensión de alimentos" y la segunda, de 14 de febrero de 2018, "sobre divorcio y fijación de pensión de alimentos".

2. Esta petición fue rechazada por el Juzgado de Primera Instancia número 6 de los de Girona al no acreditarse: (1) respecto de la primera resolución, "que se hubiera realizado la citación del demandado condenado en rebeldía"; y (2) respecto de la segunda sentencia, "por ausencia de acreditación de la firmeza" (FFJJ 3 y 4).

3. En el examen del recurso de apelación la Audiencia plantea dos cuestiones íntimamente relacionadas, que despeja en los tres primeros fundamentos de derecho: (i) la determinación del marco jurídico normativo (régimen jurídico) aplicable (FJ2); (ii) las condiciones para el otorgamiento de la autoridad de cosa juzgada y su acreditación documental; (iii) con detenimiento examina dos de estas condiciones a saber: (a) la rebeldía del demandado (declarada en la primera sentencia) y, consecuentemente, si la parte "fue legalmente citada o declarada rebelde"; y (b) la acreditación de la firmeza (de la segunda sentencia) y si cabe y con qué alcance la ejecución provisional de las medidas relativas a la obligación de alimentos declaradas provisionalmente ejecutorias en la sentencia de origen (FFJJ 3 y 4 ).

4. Respecto de la primera cuestión, la recurrente se amparaba en la Ley 29/2015, de 30 de julio, de cooperación jurídica internacional en materia civil (en adelante, LCJI). La Audiencia Provincial determina el alcance de dicha norma indicando correctamente su carácter subsidiario en presencia de norma convencional (art. 2 apartado a) LCJI). Dada la procedencia de la sentencia (Marruecos) y la materia objeto de esta (divorcio y medidas provisionales de alimentos), es aplicable el Convenio de cooperación judicial en materia civil, mercantil y administrativa entre el Reino de España y Marruecos de 30 de mayo de 1997 (en lo sucesivo, Convenio hispano-marroquí o Convenio de 1997²).

5. Respecto de la segunda cuestión, la controversia se suscita en orden a la (correcta) citación al demandado. Para la recurrente, la entrega de la citación a un primo del demandado residente en Marruecos bastaría para enervar la tacha de falta de notificación declarada por el juzgador de instancia. La firmeza de la segunda sentencia -como requisito para la ejecución- es igualmente una cuestión controvertida que la Audiencia Provincial aborda supliendo la deficiencia de argumentación de la recurrente. El punto de observación se fija en la posibilidad de ejecución provisional en España de las medidas sobre alimentos declaradas provisionalmente ejecutorias en la sentencia de origen cuando, como en el caso, no ha quedado probada la firmeza de la sentencia. Su posibilidad de ejecución provisional y su alcance son determinados en el auto objeto de este comentario. Como veremos, la Audiencia Provincial de Girona va a sostener una interpretación flexible respecto de la verificación de las condiciones previstas en el artículo 23 del Convenio de 1997, con apoyo en la LCJI en beneficio de la ejecución y la tutela internacional efectiva.

6. Siguiendo este planteamiento, abordaremos la respuesta del auto de la Audiencia Provincial ordenando el comentario en torno al examen de dos de las condiciones verificadas por el tribunal en su respuesta al recurso contra la denegación del exequatur: por una parte, la acreditación de la notificación (apartado II); y, por otra parte, la acreditación de la firmeza de la sentencia y posibles excepciones a este requisito (apartado III). Una breve reflexión conclusiva finalizará el comentario.

AAP GI 1045/2019 - ECLI: ES:APGI:2019:1045A. Fecha: 08/10/2019. Recurso de apelación núm. 760/2019.

BOE núm. 151, de 25 de junio de 1997. 


\section{Las condiciones para otorgar el exequatur de la sentencia marroquí (I): las partes han sido legalmente citadas, representadas o declaradas rebeldes}

7. Recordemos que la solicitante había iniciado en España un procedimiento de exequátur de dos sentencias dictadas en Marruecos relativas, respectivamente, al reconocimiento de una pensión de alimentos (sentencia de 2016) así como al divorcio y alimentos (sentencia de 2018). El Juzgado de $1^{\text {a }}$ instancia núm. 6 de Girona rechazó la solicitud respecto de la sentencia de 2016 "al no acreditarse que se hubiera realizado la citación del demandado condenado en rebeldía".

8. El régimen jurídico aplicable se establece en el Título III del Convenio hispano-marroqui cuyos artículos 22 a 28 establecen su ámbito de aplicación material (con expresión de las materias excluidas, art. $22^{3}$ ); las condiciones para declarar la autoridad de cosa juzgada de la sentencia en el territorio del otro Estado (art. 234); la obligación de ser declaradas ejecutivas en el Estado requerido para que pueda dar lugar a la ejecución forzosa o coercitiva (art. 24); la comprobación de oficio por parte del tribunal requerido del cumplimiento de los requisitos del artículo 23 (autoridad de cosa juzgada) y la documentación que ha de adjuntarse para dicha acreditación (art. $28^{5}$ ); y, finalmente, los efectos de la decisión de ejecución (art. 27). Sobre este particular, cabe recordar que mientras el Convenio se refiere expresamente a condiciones para alcanzar la autoridad de cosa juzgada, el sistema del exequátur en la LCJI no está "condicionado" a la superación de unas condiciones concretas, sino que la idea es que la sentencia extranjera obtiene el reconocimiento/ejecución en España "salvo que concurra algún motivo concreto y específicamente recogido en la LCJI (art. 46) que autorice su rechazo. ${ }^{6}$

Son básicamente cuatro materias: testamentaria y sucesoria; quiebra, procedimientos de liquidación de sociedades u otras personas jurídicas insolventes, conciertos y convenios análogos entre deudores y acreedores; resoluciones contenciosas en materia de seguridad social (con referencia al Convenio hispano-marroquí de 8 de noviembre de 1979); y, finalmente, en caso de medidas cautelares y provisionales, salvo las dictadas en materia de alimentos (énfasis es nuestro).

4 El régimen de condiciones se contempla en el artículo 23. Cabe señalar que no se realiza un control de la ley aplicada. El control se realiza respecto de la competencia judicial internacional del órgano jurisdiccional de origen (lo que se realiza mediante sus normas de DIPr); el respeto de los derechos de defensa (que se acredite la citación legal de las partes, representadas o declaradas rebeldes); la firmeza de la sentencia (que la resolución haya adquirido autoridad de cosa juzgada y sea ejecutiva conforme a las leyes del Estado en que ha sido dictada); que la resolución no contravenga el orden público del Estado requerido (en el que se solicite la ejecución ni contraria a otra dictada en ese mismo Estado); que haya adquirido autoridad de cosa juzgada; $\mathrm{y}$, que no exista litispendencia (que no se encuentre pendiente entre las mismas partes y por el mismo objeto ningún proceso ante algún órgano jurisdiccional del Estado requerido, antes de iniciarse la acción ante el tribunal que haya dictado la resolución que deba ejecutarse). Sobre este convenio, véase el comentario general y las referencias a las resoluciones de las Audiencias Provinciales en A. L. Calvo Caravaca/ J. Carrascosa González, Derecho internacional privado, Vol. I, Comares, 2016, p. 758. Asimismo, entre otros, las reflexiones sobre su amplia aplicación en España que ya realizase R. Arenas García, en Crisis matrimoniales internacionales. Nulidad Matrimonial, separación y divorcio, en De Conflictus Legum. Universidad de Santiago de Compostela-Publicaciones, 2004, pp. 452 ss. El estudio de F. Garau Sobrino sobre "La normativa convencional hispano-marroquí sobre reconocimiento y declaración de ejecutividad de resoluciones judiciales, documentos públicos con fuerza ejecutiva y laudos arbitrales en materia civil, mercantil y administrativa" en Derecho internacional y Relaciones internacionales, Actas de las XVII Jornadas de la AEPDIRI, 1999, pp. 167-180. Las recomendaciones sobre su correcta aplicación práctica por las autoridades nacionales (judiciales y administrativas) que realiza M. Moya Escudero, en "Recommandations issues dans les rencontres internationales sur les relations familiales et succesorales hispano-marocaines”, Paix et Securité Internationales, Num. 2, janvier-décembre 2014, pp. 167-202, esp. p. 178. Y, en particular, los trabajos de la doctrina española recogidos en Familia y sucesiones en las relaciones hispanomarroquies, (Moya Escudero, M. Dir.), Tirant lo Blanch, 2015. Y, de carácter más general, el estudio del sistema convencional bilateral español de reconocimiento y ejecución de decisiones extranjeras, que incluyen las crisis matrimoniales, que realiza J.I. PAZ ARES en "La eficacia extraterritorial de las resoluciones extranjeras en materia de crisis matrimoniales: cuestiones generales y sistemas de origen europeo y convencional", Crisis matrimoniales y sus efectos. Derecho español y de la Unión Europea. Estudio normativo y jurisprudencial (M. Guzmán Zapater / M. Herranz Ballesteros, Dirs.), Tirant lo Blanch, 2018, pp. 443-510 (especial referencial al sistema de condiciones del Convenio hispano-marroquí, pp. 508).

5 En concreto: (1) que la copia de la resolución reúna las condiciones necesarias para su autenticidad; (2) que se aporte el original del documento de notificación de la resolución, (3) que se certifique por el secretario del tribunal que la resolución no ha sido objeto de recurso ni de apelación; y (4) que se adjunte copia certificada conforme de la citación hecha a la parte que ha sido condenada en rebeldía (el énfasis es nuestro).

6 Sobre este desarrollo, in extenso, véase A. L. Calvo Caravaca/ J. CARrascosa GonzÁlez, Derecho internacional privado, $o p$, cit., p. 780-781. Sobre el efecto res iudicata en España y las sentencias de divorcio obtenidas en Marruecos, el comenta- 
9. La manifestación del derecho de defensa se lleva a cabo mediante el control de las garantías procesales. El régimen del Convenio hispano-marroquí, al igual que el régimen de fuente interna de la LCJI, exige que la decisión extranjera no haya sido dictada en rebeldía. Así pues, el control de la correcta citación al demandado resulta clave para el juzgador requerido que decretó el rechazo del reconocimiento y ejecución de la sentencia marroquí porque no consta que se entregara al demandado la cédula de emplazamiento o documento equivalente "de forma regular y con tiempo suficiente.

10. La Audiencia Provincial examina este motivo de rechazo y constata que de los hechos recogidos en la sentencia de instancia no se desprende que el demandado fuera citado personalmente o que la citación se realizara con las garantáis de su recepción. En efecto, de la sentencia se despende que el demandado no compareció y que fue su primo quien recibió la citación; que dicho primo reconoció que el demandado residía en el extranjero y que no se ha probado ni cuándo se realizó la citación ni si se hizo con la suficiente antelación para ser recibida por el demandado.

11. La Audiencia Provincial se pregunta en el FJ Tercero si podría hacerse una interpretación flexible de los requisitos establecidos en el Convenio hispano-marroqui relativos a la prueba de que los derechos de defensa del demandado no han sido vulnerados. Y llega a la conclusión, compartiendo el criterio del juzgador de instancia, de que estos fueron vulnerados porque no se ha probado documentalmente, según exige el Convenio, la legal citación de las partes mediante copia certificada conforme de la citación hecha a la parte que haya sido condenada en rebeldía (art. 28.4). Confirma así el rechazo al reconocimiento y la ejecución de la primera de las sentencias, relativa a la fijación de pensión de alimentos.

12. ¿Por qué una interpretación flexible de "los requisitos/condiciones"? El examen del respeto de los derechos de defensa y su acreditación documental ocupa un lugar destacado en la práctica judicial española en aplicación del Convenio hispano-marroquí. Recordemos que el Convenio en su artículo 23.2 establece como una de las condiciones para la autoridad de cosa juzgada que las partes hayan sido legalmente citadas, representadas o declaradas rebeldes. Y el artículo 28.4 indica, respecto de esta condición, qué ha de presentarse (copia certificada conforme de la citación hecha a la parte que haya sido condenada en rebeldía). Elegimos cinco resoluciones del año 2019 que, junto al auto objeto de este comentario, muestran una cierta flexibilidad de las Audiencias Provinciales en la interpretación del cumplimiento de esta condición y su prueba.

13. (1) En el auto de la Audiencia de Barcelona de 15 de febrero de 2019 se examinaba si se había vulnerado el derecho de defensa de la demandante (la mujer) por cuanto "al no comparecer el padre en el proceso pese a estar debidamente citado, tuvo que renunciar a sus derechos económicos, entre ellos la pensión de alimentos para sus hijos" 7 . El Juzgado de Primera Instancia había inadmitido a trámite la demanda por inadecuación del procedimiento. En el recurso la Audiencia Provincial constata que la petición no era de reconocimiento y ejecución de sentencia sino que se trataba de una nueva demanda relativa al establecimiento de medidas paternofiliales y alimentos. Advierte que, en todo caso, la sentencia marroquí era contraria al orden público español y ordena al juzgador de instancia la admisión a trámite de la demanda sobre medidas de responsabilidad parental.

14. (2) En el auto de la Audiencia Provincial de Barcelona de 26 de noviembre de 2019 la demanda de reconocimiento y ejecución de la sentencia marroquí de divorcio fue igualmente inadmitida a trámite por el juzgador de instancia al no acreditarse, entre otras, la notificación al demandado pese al

rio de A. M. BAllesteros Barros, "Res iudicata y divorcio internacional: nota al auto de la Audiencia provincial de Toledo de 7 de marzo de 2018", Cuadernos de Derecho Transnacional (marzo 2019), Vol. 11, No 1, pp.678-684. Como es sabido, el procedimiento de exequátur se regula en la LCJI (art. 42). Al respecto, el comentario de F.F GARAU Sobrino, "Artículo 42. Procedimiento de exequatur", en Comentarios a la Ley de Cooperación Jurídica Internacional en materia civil (F.P. Méndez González / G. Palao Moreno, Dirs.), Tirant lo Blanch, 2017, pp. 474-491.

AAP B 484/2019. ECLI.ES:APB:2019.484 A (FJ 2). 
requerimiento de subsanación realizado en la instancia. En el recurso, la apelante demostró que dicha documentación fue aportada después del auto de inadmisión. La Audiencia Provincial realizó, al amparo del artículo 266 LEC, una interpretación flexible sobre "la acreditación de la forma de notificación". En este sentido, con fundamento en el principio de economía procesal decretó por cumplido el requisito, revocó la resolución de instancia y ordenó la admisión a trámite la demanda de exequátur ${ }^{8}$.

15. (3) En el auto de la Audiencia Provincial de Tarragona de 4 de abril de 2019 la solicitud de exequátur de la demanda de divorcio marroquí fue denegada sobre la base de que la certificación aportada no acreditaba que "la parte demanda haya sido legalmente citada, representada o rebelde" (art. 23 del Convenio de 1997). La Audiencia Provincial, tras recordar que el mencionado artículo 23.2 del Convenio hispano marroquí es manifestación del derecho a la tutela judicial efectiva (art. $24 \mathrm{CE}$ ), también recogido en la Ley 29/2015 (LCJI), hace una interpretación flexible de la prueba de tal requisito tras constatar que el representante del demandado participó en los intentos de conciliación aunque se ausentó en la vista pública. La Audiencia considera que "hay una unidad de procedimiento" entre los intentos de conciliación y la celebración de la audiencia pública. Y en este sentido, entiende que no es necesario un nuevo emplazamiento o citación al demandado, estimando el recurso de apelación y ordenando que se ejecute la sentencia marroquí?.

16. (4) En el auto de la Audiencia Provincial de Ceuta de 17 de junio de 2019 se examina la denegación del reconocimiento de la sentencia de divorcio marroquí al faltar la documental relativa a la citación del demandado. En el recurso el recurrente acreditó que tal rebeldía no se había producido pues de la sentencia de origen se deducía que estuvo presente tanto en primera como en segunda instancia. El Ministerio Fiscal se opuso a tal pretensión por entender que de acuerdo con lo establecido en el Convenio hispano-marroquí y en la LCJI no consta ni se acredita que la sentencia afuera dictada en presencia de ambos cónyuges o en rebeldía. La Audiencia Provincial examina esta causa y se centra en los documentos establecidos en el artículo 28 del Convenio para comprobar si la resolución marroquí alcanza las condiciones del artículo 23. La conclusión para la Audiencia es clara ante la falta absoluta de las copias y documentos preceptivos. Sin embargo, se detiene en la cuestión de la (posible) violación del derecho de defensa dado que podía inferirse que no hubo tal dada la intervención del esposo en el proceso de origen. Ahora bien, entiende la Audiencia Provincial que de la sentencia de origen no se puede saber en calidad de qué actuó el recurrente (si por sí mismo o si en calidad de tercero). En esta línea confirma el auto de instancia que denegó el reconocimiento de la sentencia de divorcio marroquí por no acreditarse la contradicción procesal ni la citación de las partes ${ }^{10}$.

17. (5) Finalmente, en el auto de la Audiencia Provincial de Bilbao de 2 de julio de 2019 se examina la inadmisión de la demanda de exequatur de sentencia de divorcio marroquí al faltar la apostilla de la sentencia y la falta de constancia de la eventual rebeldía. La Audiencia Provincial sostiene que esta última objeción carece de fundamento puesto que de la documentación aportada no aparece que el juicio se hubiera seguido en rebeldía, constando además en el expediente que el demandado era conocer de la pretensión de su exesposa. Decreta en consecuencia que no ha habido ninguna indefensión ni incumplimiento de obligaciones procesales y ordena la continuación del procedimiento hasta resolver sobre el fondo ${ }^{11}$.

\footnotetext{
AAP B 9448/2019 - ECLI:ES:APB:2019:9448A (FJ 1).

9 AAP T 519/2019 - ECLI:ES:APT:2019:519A(FJ 2). Con anterioridad la misma Audiencia Provincial analizó la rebeldía en sentencia de divorcio marroquí, llegando a la conclusión, a la luz del Convenio hispano-marroquí y de la LCJI, que en el certificado de firmeza del divorcio se constata que "el demandado fue declarado en rebeldía" bastando con ello para dar por cumplida la exigencia del art. 28 del texto convencional (revocó el auto del Juzgado de $1^{\text {a }}$ Instancia de Tarragona y otorgó el exequatur). Auto de 21 de enero de 2019, comentado por L.S. Heredia SáncheZ, "Procedencia de exequátur de sentencia extranjera de divorcio dictada en rebeldía del demandado: Comentario al Auto de la Audiencia Provincial de Tarragona de 21 de enero de 2019, Cuadernos de Derecho Trasnacional (Octubre 2019), Vol. 11, No 2, pp. 636-640.

10 AAP CE 58/2019 - ECLI:ES:APCE:2019:58A (FJ Único).

11 AAP BI 1412/2019 - ECLI:ES:APBI:2019:1412A (FJ 3). En idéntico sentido el auto de la Audiencia Provincial de Huelva de 7 de febrero de 2017 - ECLI:ES:APH:2019:83 A.
} 


\section{Las condiciones para otorgar el exequatur de la sentencia marroquí (II): la resolución ha ad- quirido autoridad de cosa juzgada y ha llegado a ser ejecutiva conforme a las leyes del Estado en que haya sido dictada}

18. La acreditación de la firmeza de la segunda sentencia marroquí (2018, pretensión de divorcio y alimentos) es abordada en el auto de la Audiencia Provincial de Girona desde una doble perspectiva: por una parte, se examina su firmeza de la sentencia como requisito esencial para proceder a su ejecución en España y su acreditación; y, por otra parte, se analiza la posibilidad de su ejecución provisional toda vez que en Marruecos "ha sido declarada provisionalmente ejecutoria".

19. La firmeza de la sentencia dictada en el Estado de origen (condicionante de carácter procesal) debe probarse para ser homologada en España. Esto es lógico pues se trata de evitar reconocer y ejecutar sentencias que puedan ser revocables; de donde resulta procedente que se requiera la aportación de un documento que reconozca la firmeza de la sentencia, a no ser que la misma conste en el propio título. De acuerdo con el Convenio hispano-marroquí, la acreditación ha de realizarse mediante certificado del secretario del tribunal que haga constar que la resolución no ha sido objeto de recurso ni de apelación (art. 28.3 del Convenio). La Audiencia concluye -a la luz de los hechos probados y del propio recurso- que no hay documento alguno en el que se acredite la firmeza (condicionante de carácter formal). En la práctica judicial española la denegación se produce justamente por la falta de presentación de la documentación requerida. En efecto, la falta de presentación del certificado del secretario del tribunal marroquí que acredite que la resolución es firme implica que no es posible otorgar el exequatur (no acceder a la homologación pretendida). Tampoco en el recurso se ha alegado ni probado causa alguna que hubiera impedido la obtención de esta documentación, como así destaca el auto de la AP Girona, en clara referencia a la doctrina de nuestro Tribunal Supremo ${ }^{12}$.

20. Cabe observar que, en la aplicación del Convenio hispano marroquí, nuestros juzgados de primera instancia son estrictos en la interpretación de este condicionante material y de su prueba formal. Así, entre otros: el auto del Juzgado de Primera Instancia e Instrucción núm. 8 de Rubí, que dio lugar al auto de la Audiencia Provincial de Barcelona de 26 de noviembre de 2019, inadmitió la demanda de exequatur porque no se aportó el documento de constancia de la firmeza ${ }^{13}$; por el contrario, el auto del Juzgado de Primera Instancia e Instrucción número 6 de Ceuta declaró la fuerza ejecutiva de la demanda de divorcio dictada por un tribunal de Rabat. En el recurso de apelación, que dio lugar al auto de la Audiencia Provincial de Ceuta de 17 de junio de 2019, quedó demostrado que lo aportado no era copia de la sentencia de primera instancia sino una transcripción de una sentencia de divorcio por desavenencia, que en concreto extractaba los fallos de las resoluciones de origen ${ }^{14}$.

21. Como se ha indicado, solo las resoluciones extranjeras firmes pueden ser objeto de reconocimiento. También ha de aportarse el documento en el que conste la fuerza ejecutiva de la sentencia, toda vez que los efectos de ejecución vendrán dados por la legislación del Estado de origen y no por la ley procesal española. Esta es la cuestión que se plantea la Audiencia Provincial de Girona en el auto objeto de este comentario. Como ya hemos anticipado, la sentencia de divorcio dictada por el tribunal de Nador el 14 de febrero de 2018 señalaba que esta será provisionalmente ejecutoria en cuanto a los derechos del hijo y al derecho de vistas. Pues bien, a pesar de que la firmeza de la sentencia no había quedado demostrada con el certificado del secretario del tribunal marroquí (exigencia esta que impone el Convenio en su art. 28.3), la Audiencia Provincial entiende, con buen criterio, que por lo que hace a esta concreta cuestión cabe una interpretación favorable a la ejecución provisional de la misma, "debiendo en todo caso (...) acreditarse la firmeza de la resolución, cuando esta se produzca, e instar el reconocimiento y ejecución de la misma".

\footnotetext{
ATS, Sala $1^{\text {a }}$ de 28 de septiembre de 2004.

Cit. - AAP B 9448/2019 - ECLI:ES:APB:2019:9448 A.

14 Cit. - AAP CE 58/2019 - ECLI:ES:APCE:2019:58 A.
} 
22. Hubiera sido deseable mayor elaboración jurídica en la fundamentación de esta posibilidad, toda vez que una ejecución provisional no está prevista en el régimen convencional de aplicación. En efecto, el Convenio hispano marroquí establece conjuntamente el condicionante material para otorgar la autoridad de cosa juzgada y la fuerza ejecutiva conforme a las leyes del Estado en que se haya dictado (art. 23). Sin embargo, cuando establece el condicionante formal, es decir, la documentación acreditativa (art. 28.3) solo se pide certificación (...) de que la resolución no ha sido objeto de recurso ni de apelación. De donde, cabe la duda de si es posible otorgar en España tal efecto provisional que permite la legislación de origen (y también la española) aun cuando la sentencia de divorcio no haya alcanzado la firmeza (o esta no se haya probado en el procedimiento de exequátur).

23. La duda que se plantea la Audiencia Provincial de Girona la resuelve el propio tribunal a favor de la ejecución provisional de las citadas medidas "debiendo" en todo caso la solicitante instar un nuevo reconocimiento y ejecución de la sentencia marroqui cuando se produzca la firmeza de la misma. Cabe señalar que hoy en día, al amparo de la aplicación de la LCJI, las resoluciones judiciales extranjeras relativas a medidas cautelares $\mathrm{y} / \mathrm{o}$ provisionales se pueden reconocer, aunque no sean firmes, si se ajustan a los requisitos previstos en el artículo 41.4 de la LCJI ${ }^{15}$. En este sentido, $\mathrm{y}$ atendiendo a la idea de tutela judicial internacional efectiva de los derechos e intereses legítimos de los particulares, que subyace en el artículo 3.3 LCJI, el sistema español aboga por una la concesión del exequátur como algo normal y no extraordinario ${ }^{16}$. ¿Puede extrapolarse este espíritu de la LCJI al convenio hispano-marroquí de 1997? La Audiencia Provincial de Girona así lo hace, señalando que "debería efectuarse una interpretación favorable a la ejecución provisional de una sentencia en materia de alimentos de hijos menores, que además sería conforme con el Derecho español que también lo permite" (FJ Cuarto).

24. En este mismo orden de ideas, cabría apelar al artículo 50.3 LCJI que permite la ejecución parcial de una resolución extranjera ${ }^{17}$. El precepto está pensado, como ha señalado la doctrina, para abrir la puerta a una "ejecución o exequátur provisional" respecto de medidas cautelares extranjeras, si su denegación supone una vulneración de la tutela judicial efectiva. Esta vulneración podría producirse, por ejemplo, en el ámbito patrimonial y dentro del derecho de familia ${ }^{18}$. La Audiencia Provincial, en nuestra opinión, al favorecer una interpretación flexible de las condiciones del artículo 23 del Convenio hispano marroquí, da entrada a la ejecución provisional de la sentencia, en este caso, solo para la ejecución de las medidas establecidas a favor de los menores y que constan como ejecutivas provisionalmente en la sentencia de origen, señalando que ello no es contrario al Derecho español "que también lo permite"19.

15 Véase: F. GASCÓN InCHAUSTI, "Reconocimiento y ejecución de resoluciones judiciales extranjeras en la Ley de cooperación jurídica internacional”, Cuadernos de Derecho Transnacional, Vol. 7 (2015), pp. 158-187. J.L. IgLesias BuHigues, “Artículo 41. Ámbito de Aplicación, Comentarios a la Ley de Cooperación Jurídica Internacional en materia civil (F.P. MÉNDEZ GonzÁlez / G. Palao Moreno, Dirs.), Tirant lo Blanch, 2017, pp. 467-473, esp. p. 471.

16 J. Carrascosa González, Comentarios a la Ley 29/2015 de Cooperación Jurídica Internacional en materia civil (A. FernándeZ-Tresguerres García, Coord.), Bosch, 2019, p. 396

17 Sobre el reconocimiento parcial en la LCJI, véase el comentario de N. MARCHAL EsCALONA, "Reconocimiento y ejecución parcial de resoluciones judiciales extranjeras en la Ley de cooperación jurídica internacional en materia civil. Comentario al auto de la Audiencia Provincial de Gipuzkoa (sección 2a) núm. 120/2018, de 9 de marzo", Cuadernos de Derecho Transnacional, Vol. 11 (2019), $\mathrm{N}^{\mathrm{o}} 1$, pp. 834-840.

18 Véase esta opinión en P. JimÉnez Blanco, Comentarios a la Ley de Cooperación Jurídica Internacional en materia civil (F.P. Méndez González / G. Palao Moreno, Dirs.), Tirant lo Blanch, 2017, p. 585.

19 En el régimen del Reglamento (UE) 2019/1111, que sustituirá al R. 2201/2003, la posibilidad de declarar provisionalmente ejecutivas las resoluciones dictadas sobre el ejercicio de la responsabilidad parental se contempla en el art. 34.2. Como ha comentado F.J. Forcada Miranda, el nuevo Reglamento asume el modelo del R. 1215/2012. Así, mientras que en el Reglamento 2201/2003 (art. 28) se requería la solicitud de declaración de ejecutoriedad, en el actual R. 2019/1111 se pasa a un sistema directo de la ejecutoriedad sin que sea necesaria una declaración de fuerza ejecutiva. Un cambio de paradigma y un paso más hacia la supresión decidida del exequátur en este ámbito particular de materias del derecho de familia. Véase en F.J. Forcada Miranda, Comentarios prácticos al Reglamento (UE) 2019/1111. Competencia, reconocimiento y ejecución de resoluciones en materia matrimonial, responsabilidad parental y sustracción internacional de menores, Ed. Sepin, 2020, pp. 301-304. 


\section{Reflexión conclusiva}

25. No es infrecuente en la práctica judicial española la desestimación del exequátur de resoluciones judiciales de divorcio (con o sin declaración de medidas relativas a la responsabilidad parental y obligación de alimentos para menores) procedentes de tribunales marroquíes, país con el que existe un convenio bilateral de cooperación en la materia. Los jueces de primera instancia examinan de oficio las condiciones para el otorgamiento de la autoridad de cosa juzgada a la sentencia y advierten defectos en la prueba de estas condiciones denegando de plano la ejecución.

26. Las Audiencias Provinciales, en el examen de los recursos de apelación contra los autos denegatorios del exequatur, vienen realizando una interpretación sistemática de las condiciones del artículo 23 del Convenio hispano marroquí de 1997 en consonancia con el principio in favor executionis de la LCJI. Esta sistemática se manifiesta en una doble dirección: bien delimitando qué defectos son subsanables (incluso en la segunda instancia) y, por consiguiente, ordenando la admisión a trámite de la demanda de exequatur o concediendo directamente la ejecución. En otros casos, este examen se realiza a la luz "certificado de firmeza del divorcio" (art. 28) para verificar si del mismo puede inferirse el cumplimiento de las condiciones para alcanzar la autoridad de cosa juzgada (art. 23 del Convenio).

27. El auto de la AP de Girona no se aparta de esta línea de razonamiento que parece generalizarse, al menos respecto de sentencias de divorcio marroquíes. Mientras que en la verificación de la infracción de los derechos de defensa del demandado (primera sentencia sobre alimentos, de 2016) la interpretación es claramente favorable a la no admisión del exequatur por no quedar acreditada la entrega de la cédula de emplazamiento, en la verificación de la firmeza (segunda sentencia sobre divorcio y alimentos, de 2018) es más flexible en la medida en que pese a que la parte no acreditó documentalmente la firmeza de la resolución extranjera, el tribunal española va a dar efectos ejecutivos a las medidas declaradas provisionalmente ejecutivas en la marroquí (alimentos y derecho de visita). Con la admonición final de que ello se otorga sin perjuicio de que la solicitante del exequatur deba acreditar la firmeza de la resolución cuando se produzca e instar el reconocimiento y ejecución de la misma (Parte Dispositiva-Fallo). 